\title{
Remifentanil protects human osteoblasts from oxidative injury
}

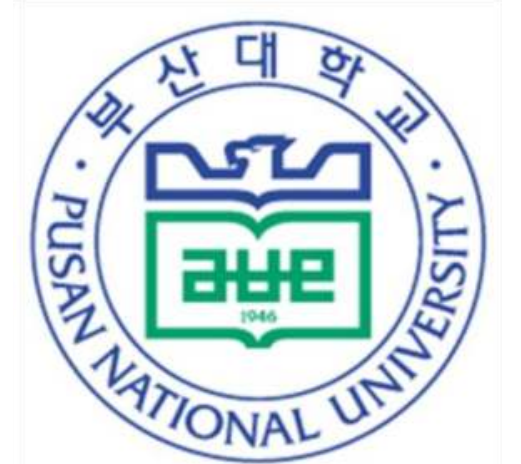

Seong-Ho Lee ${ }^{2}$, Eun-Jung Kim ${ }^{1}$, Ji-Young Yoon ${ }^{1}$, Seung-Cheol Lee ${ }^{3}$, Seung-Wan Baik ${ }^{4}$, Sang-Wook Shin ${ }^{4}$

${ }^{1}$ Pusan National University Dental Hospital, Dept of Anesthesiology \& Pain Medicine, Yangsan, Korea, Republic of, ${ }^{2}$ School of Medicine, Sungkyunkwan University, Dept of Anesthesiology \& Pain Medicine, Gyeongnam, Korea, Republic of,

${ }^{3}$ Donga Univ. Medical Center, Dept of Anesthesiology \& Pain Medicine, Pusan, Korea, Republic of,

${ }^{4}$ Pusan National University Yangsan Hospital, Dept of Anesthesiology \& Pain Medicine, Yangsan, Korea, Republic of

\section{Background}

Bone injury has been occured in various clinical situations such trauma and surgeries. During surgery, excessive reactive oxygen species (ROS) decreases the quality and quantity of osteoblasts and increases the apoptosis of osteoblasts and osteocytes. It has been reported that remifentanil decrease the production of ROS and inflammatory response. In this study, we investigated whether remifentanil has a protective effect against oxidative stress in osteoblasts or not.

\section{Materials and Method}

The groups were divided into the following groups; Control : cells were incubated at $37^{\circ} \mathrm{C}$ without remifentanil treatment, $\mathrm{H}_{2} \mathrm{O}_{2}$ : cells were exposed to $200 \mu \mathrm{M}$ of $\mathrm{H}_{2} \mathrm{O}_{2}$ for $2 \mathrm{~h}$. RPC $+\mathrm{H}_{2} \mathrm{O}_{2}$ : cells were pretreated with $2 \mathrm{ng} / \mathrm{ml}$ of remifentanil for $2 \mathrm{~h}$ before exposure of $\mathrm{H}_{2} \mathrm{O}_{2}$. $3-\mathrm{MA}+\mathrm{RPC}+\mathrm{H}_{2} \mathrm{O}_{2}$ : cells were pretreated with $1 \mathrm{mM}$ of 3-MA $1 \mathrm{~h}$ and remifentanil before exposure of $\mathrm{H}_{2} \mathrm{O}_{2}$.

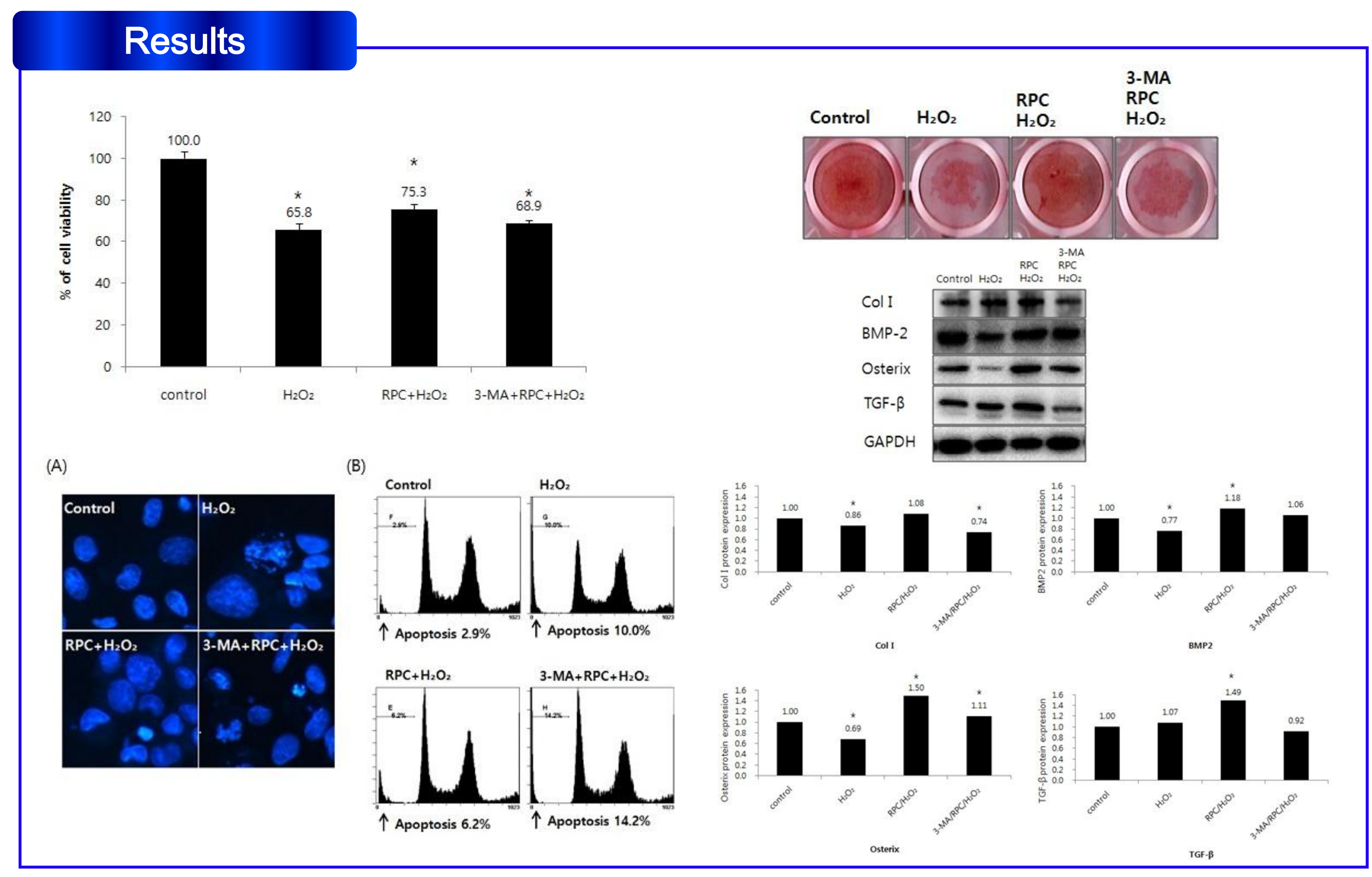

\section{Conclusions}

This study demonstrated that remifentanil reduce oxidative damage in human osteoblasts. And we showed the possibility that autophagy is related with a protective effect of remifentanil in response to oxidative stress. For clinical correlation, further clinical based researches will be needed. 